\title{
Mass Production Costing of Induction Machines for Automotive Applications
}

\author{
*Vladimir Hundak, *Tom Cox, *Gaurang Vakil and *TChristopher Gerada \\ *University of Nottingham - UK and TUniversity of Nottingham - Ningbo, China
}

\begin{abstract}
Cost is one of the key parameters of electric machines designed for automotive applications. In order to keep manufacturing cost low, it is desirable to estimate the manufacturing cost of the machine in the early stages of the design process. For this purpose, a costing algorithm for mass production of induction machines is proposed. The case study examines the impact of variations in dimension (stack length and bore diameter) of the input design on cost outputs, in order to validate the base structure of the algorithm. The overall aim of this work is to provide cost optimization of the machine design by implementation into a design optimization routine.
\end{abstract}

\section{INTRODUCTION}

Manufacturing processes in general are typically complex and consume large amounts of resources. Automotive industry is very competitive, and therefore, it is desirable to perform accurate cost estimation during the design process of a new drive for hybrid electric vehicles (HEVs) to optimize its parameters and their implications on cost. Published literature for cost estimation of induction machines (IMs) considers multiple approaches. Most basic approach for cost optimization is carried out at the material level only, not taking production costs into account $[1,2,3]$. On the other hand, [4] describes a model of an induction machine manufacturing factory and [5] presents production costs model of electrical machines in general. [4, 5] provide information useful for general understanding of processes presented in this work. A simplified cost models are proposed for understanding of tradeoffs between performance, cost and volume in [6] and optimization of a more complex system where the machine is contained is demonstrated in [7]. The work presented in [7] describes optimization of hybrid electric vehicle powertrain featuring interior permanent magnet machine. A discussion on evaluation of IM manufacturing cost based on improvement of efficiency of the machine is illustrated in [8]. The work presented in $[9,10]$ focuses on reduction of cost of small IMs by technical changes in production.

The analysis of manufacturing costs presented in [11] lacks a general method of cost estimation. Analytical calculation of production costs is the most suitable method for detailed analysis because it splits whole task into elementary parts [12]. This method was used for cost estimation of small single-phase IMs for household appliances [13] and is called activity-based costing (ABC) [14]. An example of $\mathrm{ABC}$ successful implementation into industry is presented in [15]. The work presented in this paper is also based on ABC costing method. Advanced methods for cost estimation include usage of genetic algorithms and neural networks

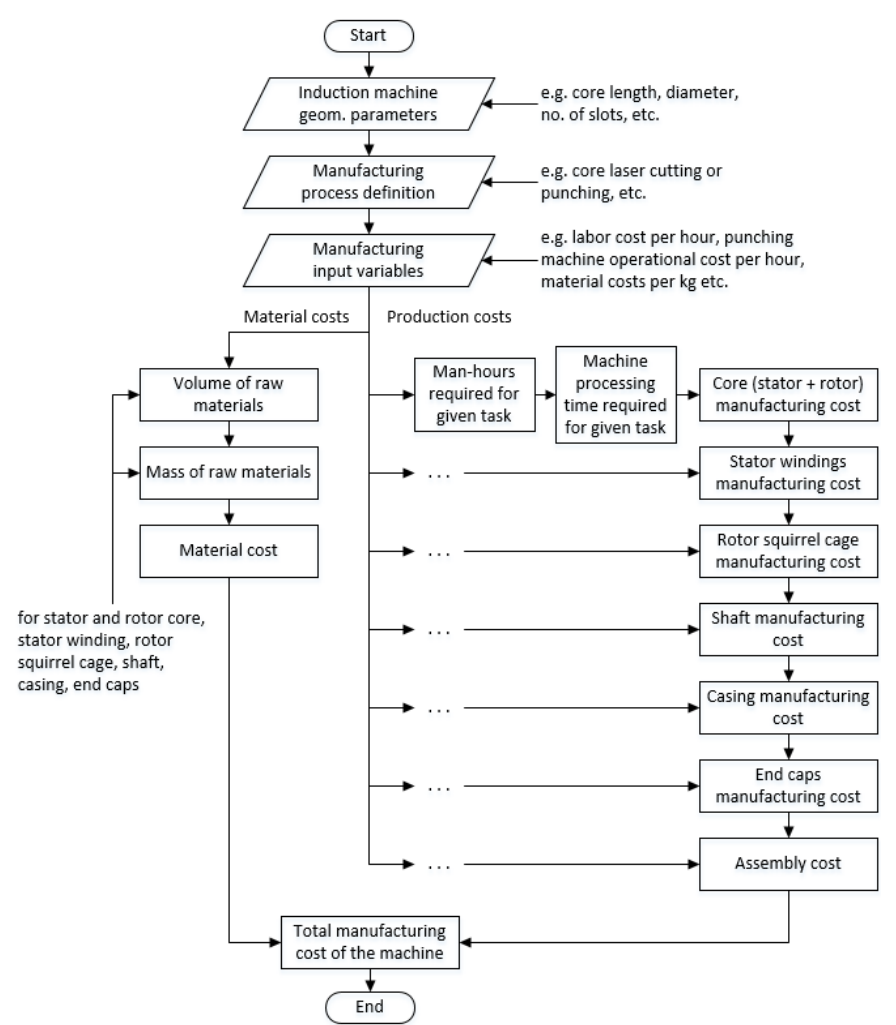

Fig. 1. Flowchart of induction machine costing algorithm.

$[1,2,3,16]$ and it was demonstrated in [16] for IMs designed for industrial applications.

\section{OVERVIEW OF THE PROPOSED PROCESS}

An induction machine costing algorithm has been developed in Matlab, following the process shown in Fig. 1. The manufacturing process of the machine was investigated at the component level at first (e.g. stator core, shaft, etc.). The cost model of each part was formulated independently as a set of equations describing all steps in the production of the given machine part. These equations calculate required amount of materials, man-hours and machine processing hours for each part. Estimated cost was calculated with consideration of machine geometry, material cost including scrap material, staff salary and operational cost of equipment used during manufacturing. A mass production cost analyzing tool was established by combining all of the related models (mentioned above) according to the machine assembly. This was implemented at the design stage of the induction machine 


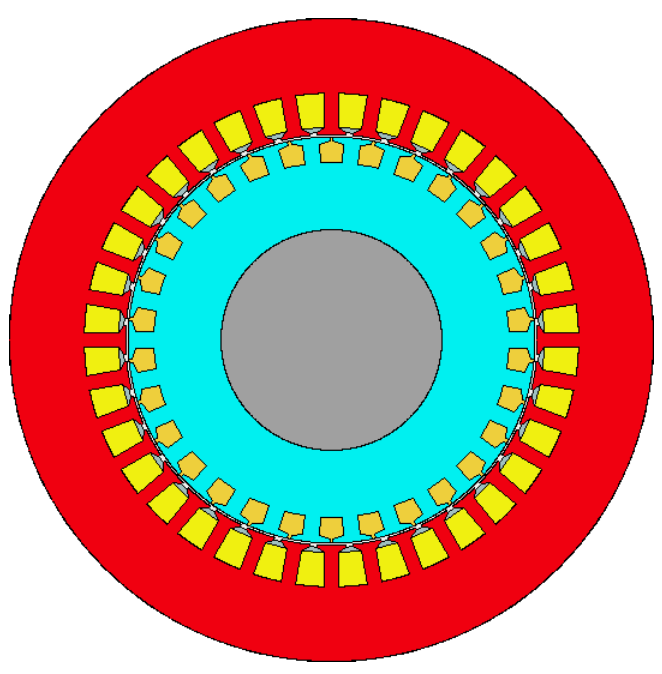

Fig. 2. Cross-section area of original machine design.

and thus, considered during the optimization process of the induction machine design.

Material costs are determined from the raw blocks of material whose dimensions are slightly larger compared to input machine design values. The only exception are copper wires used for manufacturing of windings, for which, an additional percentage of material is added on top of total length of conductors to cover material wasted in manufacturing process. Another difference in calculation is in case of core laminations. The amount of material is defined by number of laminations required to cover full stack length of core.

Calculations of production processes used in the algorithm describe an automated manufacturing line where the labor operates machines with pre-defined programs (e.g. CNC machine). The only exceptions are stacking of laminations and complete manufacturing and assembly of stator windings, which are calculated as pure human labor. Core laminations are made by punching whereas all other components (shaft, casing and end caps) are machined by $\mathrm{CNC}$ processes. A water jacket inside the casing is used as the cooling solution

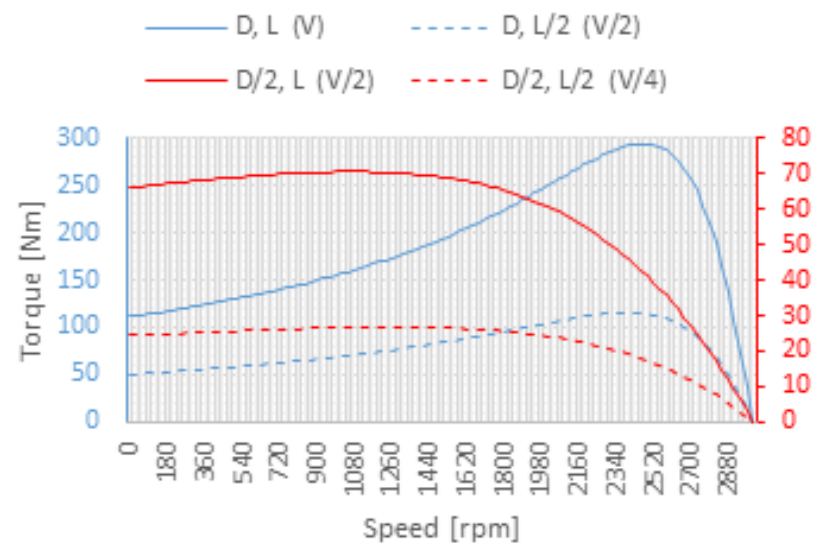

Fig. 3. Torque-speed characteristics of scaled models obtained from Motor-CAD software. for all presented results. It is assumed that the squirrel cage rotor is constructed from conductive bars and end rings that are independently cut from raw blocks of material and then brazed together using automated processes. The developed program is highly flexible and can easily adapt to any specific process of manufacturing.

The validation of this script was implemented by scaling length and diameter of a typical induction machine design suitable for application to automotive hybridization. The scaling test was performed using estimated manufacturing input parameters, including equipment running costs along with the man hours required for suggested processes.

\section{SPECIFICATIONS OF INDUCTION MACHINE DESIGNS USED FOR VALIDATION}

\section{A. Scaling of Single Machine Design}

An induction machine was investigated to validate the developed cost analysis tool. This machine was originally designed for automotive applications. Its cross-section area is shown in Fig. 2 and all important parameters are listed in first column in Table 1. Four combinations of stack length $L$ and diameter $D$ arrangements were analyzed for the validation, including the original model - i) A model with stack length halved vs the original, ii) A model with diameter halved vs the original and iii) A model with both of these dimensions (i.e. stack length and diameter) halved. The aim of this work was to validate the base structure of the costing algorithm by observing the output response as the inputs are scaled.

Combining two equations - (1) and (2), a commonly used in design procedure, results in an expression (3) defining relationship between input voltage and air gap dimensions $L$ and $D$ [17]

$$
\begin{gathered}
\phi_{m}=B \tau_{p} L \quad \rightarrow \quad \phi_{m}=B \frac{\pi D}{p} L \\
N=\frac{V}{4.44 k_{w} f \phi_{m}} \rightarrow V=4.44 N k_{w} f \phi_{m} \\
V=D L \frac{4.44 \pi}{p} B N k_{w} f
\end{gathered}
$$

where $B$ is flux density, $\tau_{p}$ is pole pitch, $p$ is number of poles, $V$ is input voltage, $k_{w}$ is winding factor, $f$ is frequency, and $\Phi_{m}$ is magnetic flux.

Input voltage is, therefore, directly proportional to both core length and air gap diameter of the machine and should be appropriately scaled with these dimensions. The chart in Fig. 3 shows the torque-speed characteristics of the four machines and it can be observed that scaling without any further optimization has a significant negative impact on performance (as expected). In case of models with halved bore diameter, their breakdown torque points lie in an area with a very high value of slip, also resulting in high losses and decreased performance. These models are subjective and 
can effectively represent the cost difference and enables to carry out the validation process for the costing algorithm. Peak torque, power and efficiency values of all four machine models are listed in Table 2.

TABLE I

PARAMETERS OF OPTIMIZED INDUCTION MACHINE DESIGNS USED FOR THE COSTING TOOL VALIDATION

\begin{tabular}{|l|c|c|c|c|}
\hline & $\begin{array}{c}\text { Original } \\
\text { design }\end{array}$ & $\begin{array}{c}D, \\
L / 2\end{array}$ & $\begin{array}{c}D / 2, \\
L\end{array}$ & $\begin{array}{c}D / 2, \\
L / 2\end{array}$ \\
\hline Number of phases & 3 & 3 & 3 & 3 \\
\hline Number of poles & 4 & 4 & 4 & 4 \\
\hline No. of stator slots & 36 & 48 & 48 & 48 \\
\hline No. of rotor slots & 30 & 42 & 42 & 42 \\
\hline External diameter $[\mathrm{mm}]$ & 269.45 & 269.09 & 134.72 & 134.15 \\
\hline Bore diameter $[\mathrm{mm}]$ & 172.32 & 172.32 & 86.16 & 86.16 \\
\hline Shaft diameter $[\mathrm{mm}]$ & 92.41 & 101.60 & 44.81 & 43.89 \\
\hline Core length $[\mathrm{mm}]$ & 106.84 & 53.42 & 106.84 & 53.42 \\
\hline Total length $[\mathrm{mm}]$ & 173.67 & 123.83 & 151.92 & 100.60 \\
\hline Air gap length $[\mathrm{mm}]$ & 1 & 1 & 1 & 1 \\
\hline No. of turns per coil & 3 & 4 & 5 & 10 \\
\hline Conductor diameter $[\mathrm{mm}]$ & 3.798 & 3.467 & 1.782 & 1.258 \\
\hline Winding layers & double & double & double & double \\
\hline
\end{tabular}

\section{B. Optimization of Scaled Models}

As scaled models serve well for validation purposes, but further optimization of these machines is required. Design optimization would solve the issue of the breakdown torque points lying in an area with a very high value of slip (and hence high losses) and provide improved designs for comparison of estimated costs for given frame size of the machine.

The optimization for each frame size was performed by using analytical equations for design of the induction machine and along with the detailed analysis of the performance. This process included set of limiting conditions and fixed values for multiple design variables. Number of phases, number of poles, bore diameter, core length, air gap length and input voltage were used as constants during the procedure. With respect to original models, external diameter value was used as constraint to allow the optimization to consider only the given frame size. As a result, the machine was optimized in terms of slot count and design for both stator and rotor, winding layout, external and shaft diameter. Parameters of final models along with original design are listed in Table 1.

\section{Performance evaluation}

Performance of all seven machine designs, including original model, three scaled down models and three optimized models were evaluated using FEA analysis. In order to locate peak torque and rated operating points, a series

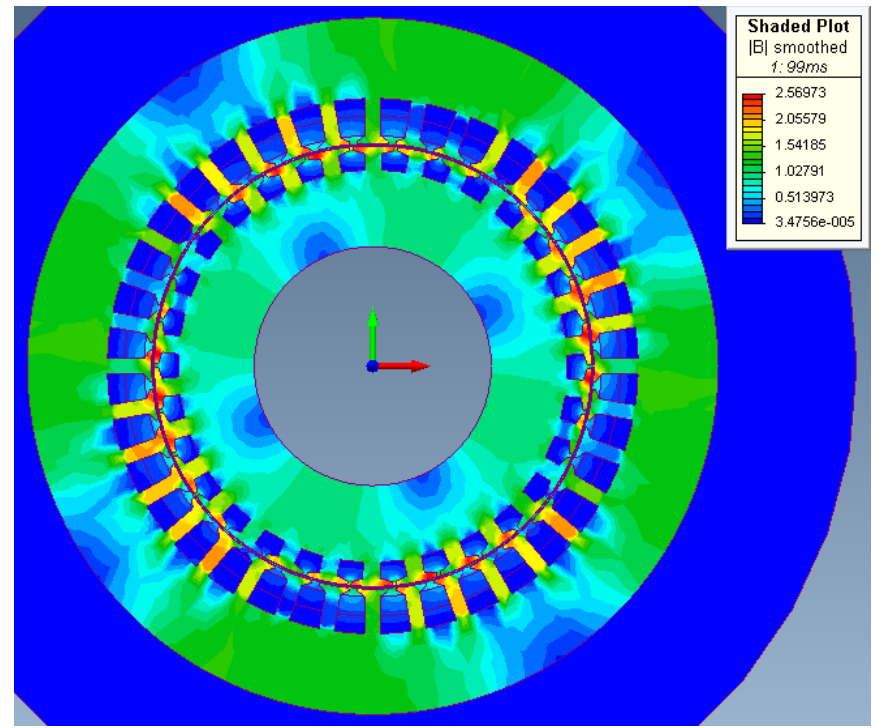

Fig. 4. Flux density profile for original design at maximum torque operation.

of simulations with varying rotor speed were performed. Rated torque point was selected as half of peak value. Speed points were selected as steps of $5 \mathrm{rpm}$ for every consecutive simulation. This method revealed torque profile around desired areas of the torque-speed curve and allowed localization of two important operating points. An example of flux density profile for this operating point is presented in Fig. 4. Obtained results are listed in Table 2 that contains performance data for all tested machines. This table shows benefits of optimization in terms of performance. All processed models offer higher torque, power and efficiency values compared to scaled machines of the same frame size. The only exception is in case of designs with halved diameter. Optimized model provides slightly lower torque and power in rated torque operation and lower torque in peak torque operation. However, this design operates with significantly higher efficiency in both cases. Another benefit of optimization is the constraint of equal voltage level that allows direct comparison of cost against original model.

\section{COSTING RESUlts}

Manufacturing cost analysis of all seven induction machine designs was performed using developed costing algorithm. Fig. 5 shows the trend in variation of manufacturing cost using per-unit values for four models - original and three scaled down designs. The base value was selected as core cutting cost of original model. In case of core cutting, only the change in length has a significant impact on cost. On the other hand, shaft and end caps are mostly influenced by changing of diameter. Manufacturing cost of squirrel cage and casing is dependent on both the dimensions, i.e. diameter and stack length.

Due to the fact that the stator winding layout is exactly the same across all four scaled down designs, winding manufacturing cost results are also equal, and therefore, omitted from Fig. 5. In order to validate this part of the script, another test was performed, where original number of stator 
slots $Q_{1}$ was halved. Another important part of cost are materials used in process of manufacturing. These results are also shown in Fig. 5.

TABLE II

PERFORMANCE PARAMETERS OF INDUCTION MACHINE DESIGNS.

\begin{tabular}{|l|c|c|c|c|}
\hline \multicolumn{5}{|c|}{ Peak torque operation } \\
\hline & $\begin{array}{c}\text { Torque } \\
T[N m]\end{array}$ & $\begin{array}{c}\text { Speed } \\
n[r p m]\end{array}$ & $\begin{array}{c}\text { Power } \\
P[k W]\end{array}$ & $\begin{array}{c}\text { Effi- } \\
\text { ciency } \\
\eta \%]\end{array}$ \\
\hline Original design (V) & 298.12 & 2535 & 79.14 & 72.86 \\
\hline L/2, D (V/2) & 90.81 & 2635 & 25.06 & 75.15 \\
\hline Optimized L/2, D (V) & 122.92 & 2725 & 35.08 & 80.72 \\
\hline L, D/2 (V/2) & 74.00 & 1440 & 11.16 & 31.01 \\
\hline Optimized L, D/2 (V) & 71.16 & 2055 & 15.31 & 53.78 \\
\hline L/2, D/2 (V/4) & 24.86 & 1800 & 4.69 & 36.68 \\
\hline Optimized L/2, D/2 (V) & 26.29 & 2175 & 5.99 & 54.77 \\
\hline \multicolumn{4}{|c|}{ Rated torque operation } \\
\hline Torque & $\begin{array}{c}\text { Speed } \\
n[r p m]\end{array}$ & $\begin{array}{c}\text { Power } \\
\text { [kW] }\end{array}$ & $\begin{array}{c}\text { Effi- } \\
\text { ciency } \\
{[\% \%]}\end{array}$ \\
\hline Original design (V) & 149.55 & 2890 & 45.26 & 91.45 \\
\hline L/2, D (V/2) & 45.47 & 2910 & 13.86 & 91.06 \\
\hline Optimized L/2, D (V) & 63.00 & 2925 & 19.30 & 92.35 \\
\hline L, D/2 (V/2) & 37.25 & 2650 & 10.34 & 75.65 \\
\hline Optimized L, D/2 (V) & 35.24 & 2775 & 10.24 & 84.99 \\
\hline L/2, D/2 (V/4) & 12.58 & 2740 & 3.61 & 74.75 \\
\hline Optimized L/2, D/2 (V) & 13.18 & 2800 & 3.86 & 83.06 \\
\hline
\end{tabular}

Complete manufacturing cost comparison in per-unit values for all seven designs is presented in Fig. 6. Base value for this chart was also selected as core cutting cost of original machine. Since core length was set as a constant during optimization process, core cutting costs are equal for models with the same frame size. Cost of squirrel cage on all optimized designs is higher due to higher amount of rotor slots. These rotors, therefore, require longer time for bar cutting and brazing. Shaft costs are similar between models of the same frame size, and depends on the diameter. The only noticeable difference is in case of optimized design with halved length. This machine features shaft with significantly larger diameter, causing increase in manufacturing cost. Differences in cost of casing for machines with the same frame size are caused by changes in total length. In case of models with halved length, stator windings on optimized machine require more space, thus longer length and higher manufacturing cost. The cost of end caps is equal for models having the same external diameter. In terms of materials, all optimized models require larger amount materials for windings and squirrel cage, thus increasing the cost. Cost of windings manufacturing is increased for all optimized models

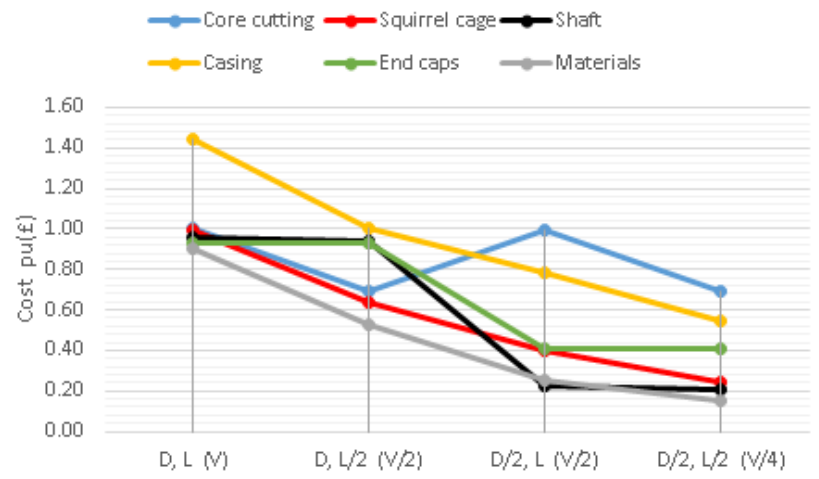

Fig. 5. Trends of manufacturing costs.

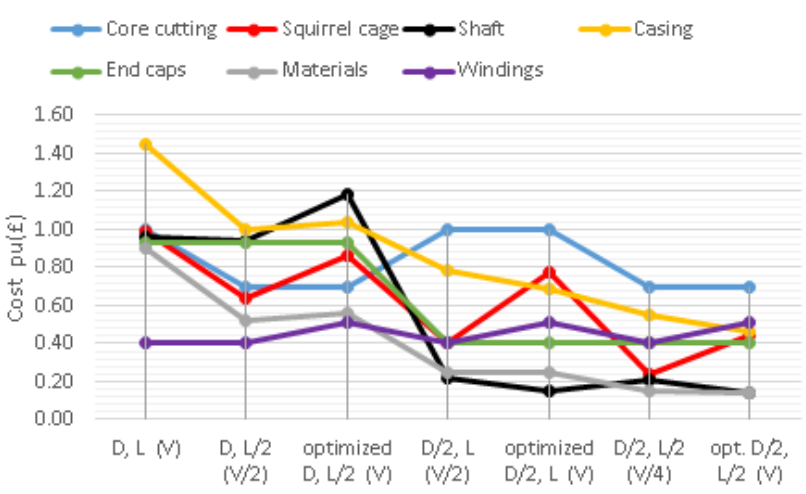

Fig. 6. Comparison of all obtained partial manufacturing results.

due to more complex layout caused by higher number of stator slots.

Total manufacturing times and costs in per-unit values are shown in Table 3. The base value for manufacturing times was selected as value of man-hours for original model. In the second table, the base value was selected as total cost of original design and base values of cost/performance ratios were selected as original model results in both cases. Since the production processes are considered to be automated, and even the winding layout is the same across all scaled down machine designs, the difference in the total man-hours is minimal. Optimized designs require larger amount of manhours in comparison with models of the same frame size due to higher complexity of their windings. On the other hand, dimension changes have a significant impact on all automated tasks. This translates into differences in manufacturing times and also into cost. In this case, optimized machines also require more time for manufacturing due to higher slot number. Longer time also reflects into higher cost compared to scaled down designs. As expected, smaller dimensions of the machine also require smaller amount of material for manufacturing, and therefore, resultant material cost decreases with volume. Total manufacturing cost of investigated machine models also decrease with smaller dimensions. However, cost per $k W$ and cost per $\mathrm{Nm}$ ratios significantly increase with volume reduction. Therefore, even though the biggest machine is the most expensive to manufacture, it is the most efficient in terms of power/cost 
and performance/cost. The only exception among scaled down models is the machine with halved diameter. This design has higher peak torque/frame size ratio compared to other machines, therefore, its cost/torque ratio is lower. Even though that optimized designs have higher total production costs, their cost/performance ratios are significantly improved compared to scaled down versions due to increase in performance. The only exception is again in case of the machine design with halved length.

TABLE III

Overview of Total Per Unit Manufacturing Costs

\begin{tabular}{|c|c|c|c|}
\hline \multicolumn{4}{|c|}{ Total per-unit manufacturing times } \\
\hline & \multicolumn{2}{|c|}{ Direct man-hours } & $\begin{array}{l}\text { Machine } \\
\text { processing }\end{array}$ \\
\hline Original design $(\mathrm{V})$ & \multicolumn{2}{|c|}{1.00} & 2.04 \\
\hline $\mathrm{L} / 2, \mathrm{D} \quad(\mathrm{V} / 2)$ & \multicolumn{2}{|c|}{0.94} & 1.74 \\
\hline Optimized L/2, D (V) & \multicolumn{2}{|c|}{1.15} & 2.10 \\
\hline $\mathrm{L}, \mathrm{D} / 2 \quad(\mathrm{~V} / 2)$ & \multicolumn{2}{|c|}{1.00} & 1.38 \\
\hline Optimized L, D/2 (V) & \multicolumn{2}{|c|}{1.21} & 1.59 \\
\hline $\mathrm{L} / 2, \mathrm{D} / 2 \quad(\mathrm{~V} / 4)$ & \multicolumn{2}{|c|}{0.94} & 1.17 \\
\hline Optimized L/2, D/2 (V) & \multicolumn{2}{|c|}{1.15} & 1.34 \\
\hline \multicolumn{4}{|c|}{ Total per-unit manufacturing costs } \\
\hline & $\begin{array}{l}\text { Manuf. } \\
\text { total cost }\end{array}$ & $\begin{array}{l}\text { Material } \\
\text { total cost }\end{array}$ & Total cost \\
\hline Original design $(\mathrm{V})$ & 0.87 & 0.13 & 1.00 \\
\hline $\mathrm{L} / 2, \mathrm{D} \quad(\mathrm{V} / 2)$ & 0.70 & 0.08 & 0.78 \\
\hline Optimized L/2, D (V) & 0.79 & 0.08 & 0.87 \\
\hline $\mathrm{L}, \mathrm{D} / 2 \quad(\mathrm{~V} / 2)$ & 0.49 & 0.04 & 0.53 \\
\hline Optimized L, D/2 (V) & 0.53 & 0.04 & 0.57 \\
\hline $\mathrm{L} / 2, \mathrm{D} / 2 \quad(\mathrm{~V} / 4)$ & 0.38 & 0.02 & 0.40 \\
\hline Optimized L/2, D/2 (V) & 0.40 & 0.02 & 0.43 \\
\hline \multicolumn{4}{|c|}{ Cost / performance per-unit ratios } \\
\hline & \multicolumn{2}{|c|}{$\begin{array}{l}\text { Cost / power } \\
\text { p.u. }(£ / k W)\end{array}$} & $\begin{array}{l}\text { Cost / torque } \\
\text { p.u. }(£ / N m)\end{array}$ \\
\hline Original design $(\mathrm{V})$ & \multicolumn{2}{|c|}{1.00} & 1.00 \\
\hline $\mathrm{L} / 2, \mathrm{D} \quad(\mathrm{V} / 2)$ & \multicolumn{2}{|c|}{2.45} & 2.55 \\
\hline Optimized L/2, D (V) & \multicolumn{2}{|c|}{1.97} & 2.11 \\
\hline $\mathrm{L}, \mathrm{D} / 2 \quad(\mathrm{~V} / 2)$ & & & 2.12 \\
\hline Optimized L, D/2 (V) & & & 2.40 \\
\hline $\mathrm{L} / 2, \mathrm{D} / 2 \quad(\mathrm{~V} / 4)$ & & & 4.84 \\
\hline Optimized L/2, D/2 (V) & & & 4.82 \\
\hline
\end{tabular}

\section{CONCLUSION}

A costing algorithm for mass production of induction machines has been demonstrated by developing a mathematical model and Matlab script for execution of calculations. The provided results validate the base structure of the algorithm and show that the program correctly represents the impact of parameter changes to the overall machine cost. The next stage of validation consists of using real-world data obtained directly from the manufacturing processes to validate the results in order to give a more complete picture of absolute cost effects. The finalized script can be implemented into a full machine design procedure, providing more options in terms of optimization of the machine costs at the design phase.

\section{ACKNOWLEDGMENT}

This work was supported by the Ningbo Science \& Technology Bureau under Grant 2013A31012 and by the Ningbo Science \& Technology Bureau under Grant 2014 A35007.

\section{REFERENCES}

[1] P. Han, Y. Chun, J. Choi, U. Seo, D. Koo, J. Lee, W. Lee, "Multi optimization of high efficiency induction motor considering cost effect," International Journal of Applied Electromagnetics and Mechanics, vol. 39, no. 1-4, pp. 733-737, 2012.

[2] A. S. Sindekar, A. R. Agrawal, "Cost and Performance Optimization of Induction Motor Using Genetic Algorithm Technique," International Journal of Electrical Engineering \& Technology, vol. 4, no. 2, pp. 443 449, April 2013.

[3] S. Mallik et al., "Efficiency and Cost Optimized Design of an Induction Motor Using Genetic Algorithm," in IEEE Transactions on Industrial Electronics, vol. 64, no. 12, pp. 9854-9863, Dec. 2017.

[4] C. L. Tucci, J. H. Lang, R. D. Tabors and J. L. Kirtley, "A simulator of the manufacturing of induction motors," in IEEE Transactions on Industry Applications, vol. 30, no. 3, pp. 578-584, May/Jun 1994.

[5] P. Fyhr, M. Andersson and J. E. Ståhl, "A modular framework for evaluation of electrical machine production costs," 2013 3rd International Electric Drives Production Conference (EDPC), Nuremberg, 2013, pp. 1-5.

[6] G. D. Olavarria, A. Reinap and M. Alaküla, "Cost estimation of electric traction machine and gearbox for a hybrid vehicle application," 2014 4th International Electric Drives Production Conference (EDPC), Nuremberg, 2014, pp. 1-5.

[7] G. Domingues, A. Reinap and M. Alaküla, "Design and cost optimization of electrified automotive powertrain," 2016 International Conference on Electrical Systems for Aircraft, Railway, Ship Propulsion and Road Vehicles \& International Transportation Electrification Conference (ESARS-ITEC), Toulouse, 2016, pp. 1-6.

[8] Parasiliti F., Villani M. (2000) Evaluation of the Design Options and Cost Impact of Improving Induction Motor Efficiency. In: Bertoldi P., de Almeida A.T., Falkner H. (eds) Energy Efficiency Improvements in Electronic Motors and Drives. Springer, Berlin, Heidelberg.

[9] E. Vitkova and V. Hajek, "Optimization of costs related to production of small electric machines," 2016 International Symposium on Power Electronics, Electrical Drives, Automation and Motion (SPEEDAM), Anacapri, 2016, pp. 442-446.

[10] E. Vitkova and V. Hajek, "Impact of technical changes in the production of small electric machinery on costs," 2016 IEEE 16th International Conference on Environment and Electrical Engineering (EEEIC), Florence, 2016, pp. 1-5.

[11] Mechler, G.C.: Manufacturing and Cost Analysis for Aluminum and Copper Die Cast Induction Motors for GM's Powertrain and R\&D Divisions. Degree thesis, Massachusetts Institute of Technology (2010).

[12] Germani, M., Mandolini, M., Cicconi, P.: Manufacturing cost estimation during early phases of machine design. In: 18th International Conference on Engineering Design ICED 2011, Copenhagen, Denmark, August 15-18, vol. 5, pp. 124-134 (2011).

[13] Cicconi P., Germani M., Mandolini M., Marconi M. (2014) Tool for Life Cycle Costing of Electric Motors during the Early Design Phases. In: Zaeh M. (eds) Enabling Manufacturing Competitiveness and Economic Sustainability. Springer, Cham.

[14] B. Popesko, "ABC Application Methodology for Manufacturing Industries," E+M Ekonomie a Management, 1, pp. 103-115, 2010. 
[15] N. Tu and D. Zhang, "How much does it cost to make it? Product costing in a Chinese small manufacturing company," 2010 8th International Conference on Supply Chain Management and Information, Hong Kong, 2010, pp. 1-9.

[16] M. Ikeda and T. Hiyama, "ANN based designing and cost determination system for induction motor," in IEE Proceedings Electric Power Applications, vol. 152, no. 6, pp. 1595-1602, 4 Nov. 2005.

[17] I. P. Kopylov a kolektiv, "Stavba elektrických strojů," Moscow, Russia: Energija, 1980. (Czech translation) 